\title{
Research on Artwork Pricing of China
}

\author{
Zhang Aolei \\ South China University of Technology, Panyu District, Guangzhou, Guangdong \\ 594445667@qq.com
}

\begin{abstract}
To provide reference for market participants and policy makers, this paper introduced the present situation of art auction market, summarized the main methods of Chinese artwork pricing, analyzed the existing problems of artwork pricing in China and put forward suggestions to perfect present pricing mechanism of Chinese art market. Research shows that external conditions, scarcity of artworks and characteristics of auction are the important factors to influence the price of art. Influencing factors analyzing, comparable comparison pricing, arithmetic average pricing and the Hedonic method are the main methods of artwork pricing in China. Completing relevant laws and regulations, cultivating professions for artwork pricing and completing electronic database of art market could help to complete Chinese artwork pricing mechanism.
\end{abstract}

\section{Keywords: Artworks, Art Market, Influence Factors, Pricing}

\section{Background: Market of Art has Run into Adjustment Period}

In recent years, as an investment driven market, Chinese art market has become the beneficiary of excess liquidity at the macroeconomic level and the overflow fund of real estate policy restrictions and down trend of stock market. At the same time, artworks has become the important carrier of the gift economy in the past 10 years. However, these positive factors have undergone drastic changes in the past two years. As the consequence of macroeconomic structural adjustment, liquidity squeezing and China's anti-corruption efforts, bubbles in art market is gradually disappearing. The market has entered the adjustment stage, shows the trend of high demand for scarce resources and obvious changes in different artwork plates.

\section{Main Factors that Influence Artwork Price}

\subsection{Macroeconomic Conditions}

The economic value of a work of art depends mainly on its intrinsic value, but like other commodities or investment goods, art cannot be completely divorced from a certain macroeconomic environment, its economic value is inevitably affected by macroeconomic indicators. Under the premise of the recognition of art, the adequacy of funds affects the achievement of transactions and thus the price of artworks.

He Jiangxu (1994) described the importance of macroeconomic conditions to the prices of collectibles, considered that socio-economic development is the most important factor in the determination of the price of art. Deng Wei (2014) studied the external factors influencing the pricing of art from the aspect of narrow money supply (M1), which is the measurement of the national macroeconomic trends, and found that when the amount of M1 in the market increases, the auction price of artwork also shows increasing trend. Chang Huabing (2006) explored the price of collectibles, held the idea that works of art belong to the category of superstructure, which is a part of the spiritual life that people pursue after fulfilling the material needs of life. More prosperous the economy is, the higher the standard of living, the market value of artworks are also higher. 


\subsection{Scarcity of Artworks}

Although economists have different theoretical explanations, they all focus on the direct impact of social consumption demand and commodity scarcity on commodity prices. In the field of art, consumer demand and the scarcity of contradictions, the impact of market prices more direct. Take cultural relics for example, they are non-renewable cultural resources. In the long historical years, natural damage and man-made damage is very serious, the survival of cultural relics from the total is not much, the precious cultural relics are mostly protected by museums and protection agencies so that they cannot enter the market circulation. With antique art market continues to heat up, the collection level continues to improve, the market price will be pulled up sharply.

\subsection{Auction Characters of Artworks}

A good auction organization can play a great role in the determination of price of artwork. The auction house can influence the auction price of the works of art from two aspects.

First of all, high credibility of large-scale auction house could attract more collectors or investors to put their collection boutiques into the auction process. Combining high quality auction house with high quality works of art may have greater chance of producing high-priced artworks.

Secondly, the probability of fake shot and mock auction is relatively small in the auction house with good credit. On the one hand, a good auction house often has a larger scale and more standardized management, tends to pay more attention to their market credibility, and be more careful about the precaution of fake shooting and mock auction. On the other hand, large-scale auction house has a more powerful professional team, could identify the authenticity of artworks accurately, which could easily lead to high-priced works.

\section{Artwork Pricing Methods in China}

Because of the relatively short time of development of the domestic art market, there are few quantitative studies on art pricing, while present studies mostly concentrated on qualitative analysis such as the influence factors of collectors' price.

\subsection{Analyzing Influencing Factors of Artworks}

China's scholars has made some analysis about factors that influence the prices of artworks, including the artist's fame, the authenticity of the work, the publication time, the subject matter, etc. Li Cuiqiao (2011) analyzed the factors influencing the economic value of artworks from the aspects of economic environment factors and collectors' own factors, thought that besides the characteristics of artworks, the economic factors such as macroeconomic situation, money supply and interest rate could also influence the price of artworks to some extent. Yin Yutong (2014) thought that not only the macroeconomic situation, social and cultural quality, social habits, packaging, hype and national policy would also affect the prices of collectibles from different degree.

\subsection{Comparable Comparison Pricing}

Comparable comparison pricing refers to the comparison of an artwork with other works in the market that have the same or similar attributes (such as the same author, the same version and the same age), estimate the price by reference to the price already in the market. The method is simple and easy to operate, but exact price could not be simply estimated in this way because of the high degree of heterogeneity of the art market. It is not accurate to determine price simply by assessors' personal experience or preferences, with strong individuality and arbitrariness.

\subsection{Arithmetic Average Pricing}

The arithmetic average method is similar to the average price method in foreign countries, estimating average price of an artist's work by calculating the average price per unit of an artist at each time. Because this method only considers the single factor such as artwork's area or volume, 
ignoring other important factors such as macroeconomic situation, creation time, market environment, etc. It is also simple and random, and the accuracy is not high.

\subsection{Hedonic Method}

In recent years, with the in-depth study of the Hedonic method, Chinese scholars have begun to apply the Hedonic model to the valuation of artwork auction and the construction of the price index of collectibles. The Hedonic method is a pricing method to discuss the relationship between product price and its characteristics. Hedonic in Greek has the meaning of "happy", its economic significance means the size of the utility that consumers obtained from the consumption of goods or services. The method considers that the utility of a commodity is determined by its implied attributes and characteristics, the price of the commodity is the comprehensive expression of its various characteristic prices, and the change of the characteristic price leads to the change of the commodity price. The basic form of Hedonic function is

$$
\mathrm{p}=\mathrm{f}\left(\mathrm{x}_{\mathrm{i}}\right)
$$

In this formula, $\mathrm{p}$ stands for the price of the commodity, and $\mathrm{x}_{\mathrm{i}}$ stands for the characteristic variables of the commodity. For any one of the characteristic variables, we take the derivative of any characteristic variable and get the Hedonic price of a single characteristic variable

$$
\frac{\partial p_{i}}{\partial x_{i}}=\frac{\partial f\left(x_{i}\right)}{\partial x_{i}}, i=1,2,3 \ldots n .
$$

The economic significance of the formula is the change in the total price of the commodity $\mathrm{p}_{\mathrm{i}}$ caused by the increase of one unit of the characteristic variable $\mathrm{x}_{i}$ while other characteristics remain unchanged. The linear form is

$$
\mathrm{p}_{\mathrm{t}}=\beta_{0}+\sum_{\mathrm{j}=1}^{\mathrm{m}} \beta_{\mathrm{j}} \mathrm{x}_{\mathrm{tj}}+\varepsilon_{\mathrm{t}} .
$$

In the formula, $\beta_{\mathrm{j}}$ is the corresponding regression coefficient of the characteristic variable, which means the change of the commodity price caused by one unit increasing of the characteristic variable $\mathrm{x}_{\mathrm{t}}$, while other conditions remains unchanged. $\beta_{\mathrm{j}}>0$, means that the increase in commodity characteristics of the variable will lead to increased commodity prices. Conversely, resulting in declined commodity prices. $\varepsilon_{t}$ is the residual, which mean is zero, independent of other variables, $p_{t}$ is the price for period $t$, while $\beta_{0}$ is a constant term.

The linear form of the Hedonic model is simple and can be used in many cases, but the model has the disadvantage that it assumes that the regression coefficient remains the same. When a characteristic variable increases by one unit, price changes corresponding to the unit, implies the marginal utility is constant, which is inconsistent with the law of diminishing marginal utility. The law of diminishing marginal utility means that as the quantity of commodity consumption increases, the marginal utility it brings will diminish. Therefore, the form of linear function is very limited in some practical circumstances.

In addition, Hedonic model also has semi-logarithmic form, double logarithmic form, Box-Cox transform and other forms, different forms of the estimation may lead to different results. Under normal circumstances, most of the researchers set the initial form of the function with their existing knowledge and experience, and then continue to modify the form of the function until sample data could be well fitted. 


\section{Existing Problems of Artwork Pricing in China}

\subsection{Policy Level: Incompleteness of Relevant Laws and Regulations}

Fake shooting and mock auction are the most striking problem in our art industry, any pricing method would lose their meaning in the face of fakes. Now fake art has been moving into organized, regional, and high-tech direction, fake groups possess raw materials, equipment and relative labor, forming services of large-scale and mature methods. These fake phenomenon prevented many powerful participants from entering the art market, greatly damaged the market confidence of participants and seriously affected the healthy development of the art market.

\subsection{Market Level: Shortage of Professionals in the Art Market}

The development of the art market relies on talents in artistic creation, art brokers, art identification talents and art market arbitration. However, due to the rapid development of the Chinese art market, the corresponding personnel training did not keep up with the need of art market, the overall professional quality of employees is not high, complete series of personnel could not be formed yet. Market talent cultivation largely depends on personal talent and interest, which caused difficulties in the mass production of talents, which also directly caused a serious imbalance of supply and demand of such personnel.

\subsection{Academic Level: The Lack of Relevant Research on Artwork Pricing}

The existing research on the pricing mechanism of artworks provides an important reference for setting up the mechanism of price determination of artworks. However, because of the lack of data, the present methods of pricing often ignoring other important factors in determining price of artworks when put emphasis on only one factor, the comprehensive effect of market, cost, utility, time period and information is rarely being considered. What's more, the quantitative study on artwork pricing is still few, which also influence the progress of price decisions of works.

\section{Measures to Improve the Pricing Mechanism of Chinese Art Market}

\subsection{Complete Relevant Laws and Regulations to Crack down Counterfeits}

At present, the pricing system of Chinese art is lacking, and the expert qualification is vague. The series of problems requires the government to formulate a professional code for the authentication of authenticity, promote the standardization and legalization of market of arts from the aspect of standard production, value discovery, auction circulation, evaluation and pricing based on the full consideration of the specificity of Chinese art market.

\subsection{Cultivate Talents and Professions for Artwork Pricing}

As the severe shortage of artwork valuation talents, the cultivation of relevant talents is very urgent. The first way is to establish the mechanism of combining enrollment with universities and colleges of recruiting students in order to reserve highly educated talents for artwork valuation. Secondly, specialized training channels should be set up to train special professional human resources for the art industry. In addition, responding to the constantly changing needs of the talents of art industry should also be taken into consideration in the talent cultivation process.

\subsection{Complete the Electronic Database of Art Market for further Development}

In order to improve the prediction level and forecast technology of art price, China should pay attention to the construction of electronic database of art market. The information of art market includes the establishment of the art market index, the artist's database, the database of art institutions, the database of works of art, as well as other information databases that can be managed. It is eager to establish a scientific, rational, unified and comprehensive art market 
information system with standardized and stable information collection channels, specialized agencies and specialized personnel to collect.

\section{References}

[1] He Jiangxu. Artwork Investment: A unique price[J]. Investment Theory and Practice, 1994.

[2] Deng Wei. Study on the External Effect Factors of Art Auction Price[D]. Hunan University, 2014.

[3] Chang Huabing. Study on the Price Decision and Investment Strategy of Artworks[J]. The Friend of Accountant, 2006.

[4] Li Cuiqiao. Art Market Trends and Value Analysis in China[D]. Tianjin University, 2011.

[5] Yin Yutong. The Research of Pricing the Ceramic Artwork[D]. Ceramic Institutes of Jingdezhen, 2014.

[6] Liang Zhiyan. Evaluation of Quality of Life in Guangdong Province base on Hedonic Model[D]. South China University of Technology, 2014.

[7] Lu Xiaohong. Research on the Hedonic Price Indexes of Chinese Contemporary Paintings[D]. Nanjing University of Aeronautics and Astronautics, 2009.

[8] Iain Robertson. Understanding International Art Markets and Management[M]. Chongqing University Press, 2013.

[9] Noah Horowitz. Art of the Deal Contemporary Art in a Global Financial Market[M]. Northeast University of Finance and Economics Press, 2013.

[10] Godfrey Barker. Vanity and Excess[M]. Commercial Press, 2014. 